\title{
Performance of a Wind Turbine Blade in Sandstorms Using a CFD-BEM Based Neural Network
}

\author{
Iham F. Zidane ${ }^{1,2 *}$, Greg Swadener², Xianghong Ma², Mohamed F. Shehadeh³, Mahmoud H. \\ Salem ${ }^{1}$, Khalid M. Saqr ${ }^{1}$
}

[1] Mechanical Engineering Department, College of Engineering and Technology, Arab Academy of Science, Technology and Maritime Transport (AASTMT), 1029 Abu Kir, Alexandria - Egypt [2] School of Engineering and Applied Science, Aston University, Aston Triangle, Birmingham, B4 7ET, U.K

[3] Marine Engineering Department, College of Engineering and Technology, Arab Academy of Science. Technology and Maritime Transport (AASTMT), 1029 Abu Kir, Alexandria - Egypt

*Corresponding Authors: Greg Swadener

Iham F. Zidane
Email: J.G.SWADENER@aston.ac.uk

Email: iham_zidane@aast.edu

\begin{abstract}
In arid regions, such as the North African desert, sandstorms impose considerable restrictions on horizontal axis wind turbines (HAWT) which have not been thoroughly investigated. This paper examines the effects of debris flow on the power generation of HAWT. Computational Fluid Dynamics (CFD) models were established and validated to provide novel insights on the effects of debris on the aerodynamic characteristics of NACA 63415. To account for the change in chord length and Reynolds number along the span of the blade and the 3D flow patterns, the power curves for a wind turbine were obtained using the Blade Element Momentum (BEM) method. We present a novel coupled application of neural network, CFD and BEM to investigate the erosion rates of the blade due to different sandstorm conditions. The proposed model can be scaled and developed to assist in monitoring and prediction of HAWT blade conditions. This work shows that HAWT performance can be significantly diminished due to the aerodynamic losses under sandstorm conditions. The power generated under debris flow conditions can decrease from 10 to $30 \%$ compared to clean conditions.
\end{abstract}

Keywords: wind energy; wind turbine blade aerodynamics; debris flow; surface roughness; CFDBEM model; neural network 


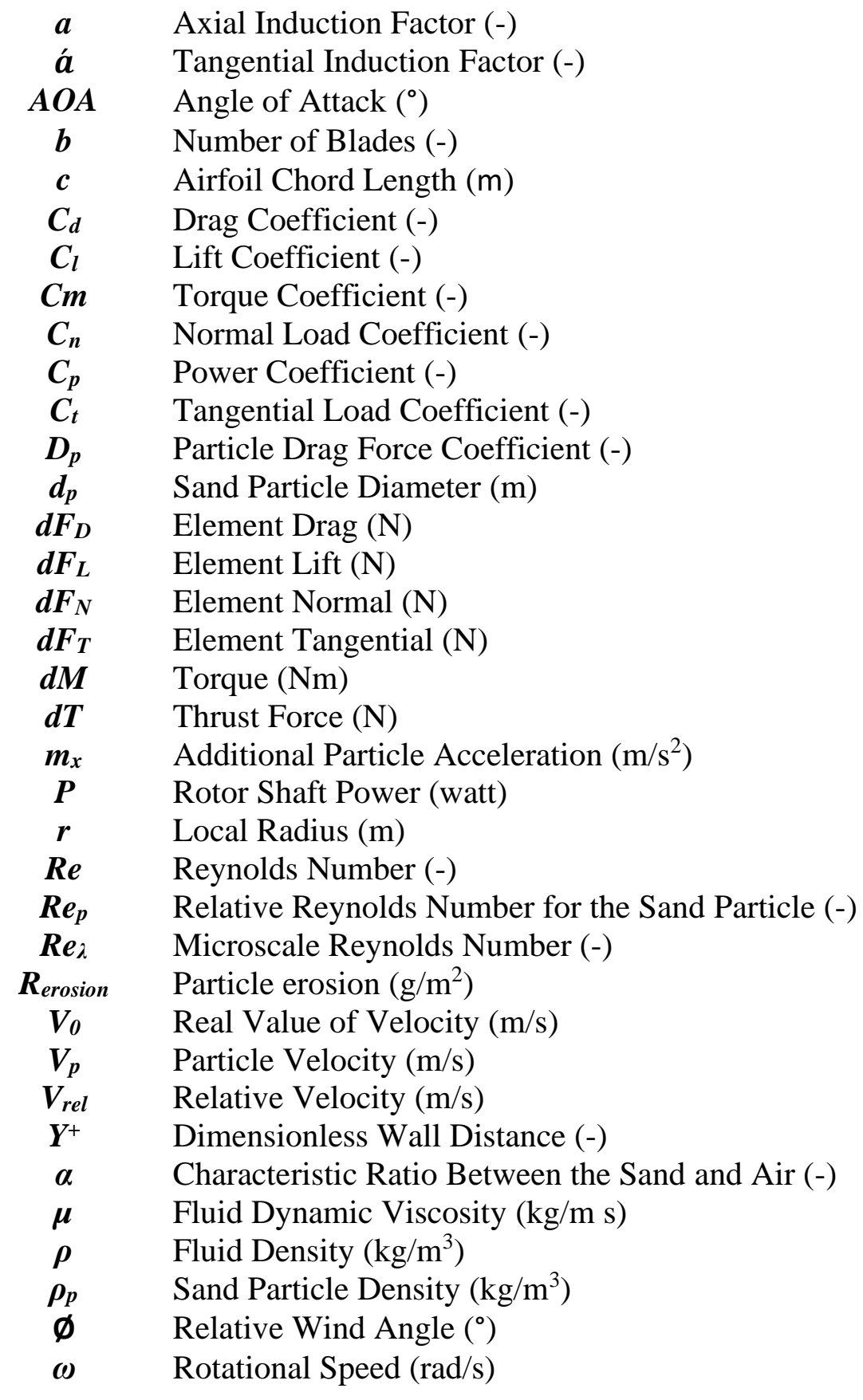




\subsection{Introduction}

In aeronautics, the determination of airfoil performance is vitally important. Computational Fluid Dynamics (CFD) and Blade Element Momentum (BEM) approaches are the leading methods used to simulate wind turbine blade performance. The BEM method analyses the flow field and blade aerodynamics, to calculate the rotor shaft torque and maximize the power generated[1-5]. BEM is fast with low computational cost, and implementation is relatively simple. However, CFD is more accurate and provides more detailed results, but incurs higher computational cost [5]. The CFD-BEM mixed approach was used in designing HAWT blades and predicting the wind turbine performance [5]. For example, Esfahanian et al. [6] determined the aerodynamic coefficients of span wise 2D sections of NREL Phase II wind turbine blades using CFD and then use BEM to predict the turbine performance. The CFD-BEM mixed approach had a much lower computational costs than the CFD-only approach yet a high degree of accuracy was obtained, which was verified using experimental results. Yang et al. [7] used a 2D CFD simulation to derive the lift and drag coefficients. The extracted airfoil data were input directly into a BEM code, which was firstly compared with experimental data for the axial and tangential forces on the blade. Then, they used these derived airfoil data sets to determine the axial and tangential forces for different blade pitch and wind velocity. Good agreement was obtained compared to experiments. On the other hand, the CFD-BEM model has also been used for other applications such as tidal stream turbines [8] and marine current turbines [9].

Research concerning the performance and deficit in energy yield of horizontal axis wind turbines (HAWT) for locations subject to dust and sand abrasion is still incomplete, while arid regions are a key focus for further development of large scale wind farms [10-12]. Akour et al. [13] used BEM theory for the blade design of airfoils BW3, A18 and SG6043. To account for changes in the blade chord length along the span and 3D flow patterns, the power coefficients of each blade was obtained using the software package QBlade. The simulation results were validated using a prototype tested in open air environment. Also, Darbandi et al. [14] obtained the blade aerodynamics coefficients using 
1 CFD simulation after validating against experimental data for a 1 megawatt wind turbine airfoil. The

2 CFD results proved that the blade roughness could effectively reduce the aerodynamic coefficients of

3 a clean airfoil. BEM theory was used to predict the performance of the 1-megawatt wind turbine blade.

4 Results showed that due to the rough surface the 1-megawatt wind turbine could be faced with $25 \%$

5 reductions in its annual energy production. In addition, Pechlivanoglou et al. [15] studied the

6 aerodynamic effects of various types of roughness-related shape deviations on wind turbines using

7 XFoil investigations. The XFoil simulation results were validated using wind tunnel measurements.

8 Measurements of power produced by wind turbines operated in sandy conditions were also used to

9 determine the actual effects of rough surfaces. Power predictions made using the state BEM method

10 were correlated with the actual power measured.

11 Artificial neural network (ANN) algorithm was used for wing sections and airfoils performance

12 optimization in various research studies. Important contributions are made by ANN in the airfoil

13 designs and the tip speed ratio (TSR) selection. For instance, Chen and Agarwal[16] proposed a genetic

14 algorithm with an ANN to optimize the wind turbines' flatback airfoils. The technique was proved to

15 find the optimal flatback airfoils. A neuro-fuzzy inference system was introduced by Ata and Kocyigit

16 [17] in application of wind turbine in order to estimate its TSR and power factor. Proposed neuro-

17 fuzzy inference system was shown by the model that it improves the conventional methods

18 performance. Yurdusev et al. [18] investigated the optimum TSR of the wind turbine airfoil designs

19 hugely used in practice as well. A demonstration of a multi-layer feed-forward neural network-based

20 model was done. The ANN proposed model's results proved that it is fast and accurate. It showed that

21 the algorithm can be modified into other airfoil designs easily due to the neural networks'

22 generalization and adaptable capabilities. In Mortazavi et al. [19], the airfoil design for the blade

23 sections of HAWT were done. They used computational fluids dynamics to train their ANN algorithm

24 in order to obtain a Pareto optimal set of solutions for the airfoil section's geometrical characteristics.

25 Some studies in literature applied ANN for fault classification were carried out in the past decades, 
where the monitored component could be discovered by the method whether it is faulty or not.

2 Saravanan and Ramachandran[20] for instance, developed an ANN with a high potential in monitoring

3 the fault conditions of the gear box. Moreover, a multi-layer back propagation neural network-based

4 model was used by Momoh and Button[21] for detecting any Direct Current arcing faults in a

5 spacecraft used by NASA in its experimental set up. The operator can only know if the component

6 was failed or not using that way. Fault development or estimation cannot be tracked by the Operator.

7 On the other hand, the methodology to automatically predict early faults of wind turbine main bearings

8 was shown by Zhang [22] . This is done by analyzing SCADA data based on ANN.

9 The main aim of the current study is to analyze HAWT performance and the energy yield

10 deficit due to debris flow using CFD-BEM modelling. Also, a new technique is proposed using ANN

11 to predict the amount of erosion occurred at different debris flow conditions. The results will provide

12 wind turbine designers with a method to estimate the performance of wind turbines installed in dusty

13 environments and its change over time.

\subsection{CFD-BEM Model}

The 3D wind turbine performance is predicted using QBlade software, because its results have

16 been verified by several researchers by comparison with wind tunnel test data and results from full

17 scale wind turbines [23]. QBlade software uses a BEM code that is based on an algorithm developed

18 by Hansen [24].

In the presented study, QBlade software was used to compute the aerodynamics of a wind

20 turbine made of three blades of 20.5 meters in length. Figure 1 presents the layout of the wind turbine

21 blade and the airfoil used which is NACA 63415. Individual data sets for clean and rough conditions

22 due to debris flow were prepared according to the results obtained by CFD. These results represent the

23 lift and drag coefficients of the chosen airfoil over an angle of attack range from $0^{\circ}$ to $10^{\circ}$. 
The basic assumptions used follow from the assumptions of the BEM theory, which is

$17 \quad \frac{\partial u_{\mathrm{i}}}{\partial x_{\mathrm{i}}}=0$

$18 \frac{\partial}{\partial t}\left(\rho u_{i}\right)+\frac{\partial}{\partial x_{j}}\left(\rho u_{i} u_{j}\right)=\frac{\partial p}{\partial x_{i}}+\frac{\partial}{\partial x_{j}}\left[\mu\left(\frac{\partial u_{i}}{\partial x_{j}}+\frac{\partial u_{j}}{\partial x_{i}}\right)-\overline{\rho u_{\imath}^{\prime} u_{\jmath}^{\prime}}-\alpha \rho_{p} \frac{\partial v_{p i}}{\partial t}\right.$

summarized as:

- The blade is discretized into segments.

- Any aerodynamic interaction between segments is neglected. software Package.

\subsection{CFD Model Description and Simulation Details:} equations are: NACA 63415 airfoil. The experiments were conducted at a Reynolds number of $1.6 \times 10^{6}$.

- Lift and drag forces on the blades are determined using the airfoil characteristics.

- The wind turbine performance is determined by the BEM method using the Qblade

- While the aerodynamic interaction is neglected in determining the lift and drag coefficients, Qblade makes a Glauert correction for the aerodynamic effects of the neighboring elements. In the current study, a control approach, maximum power point tracking (MPPT), is used to determine the optimal tip speed ratio (TSR) to use in the operation of the stall-regulated system [5].

Reynolds-averaged Navier-Stokes (RANS) equations were used to simulate two-dimensional, viscous, incompressible flow. The continuity equation and momentum equation based on RANS

where $\alpha$ is the sand to air characteristic ratio, $\rho_{p}$ is the particle density and $V p$ is the particle velocity. CFD simulations for clean air flow conditions were run for comparison with wind tunnel experimental data taken from [25] to verify the numerical model for the free-stream flow over the

A comparison between the numerical results at Reynolds numbers of $1.6 \times 10^{6}, 460 \times 10^{3}$ and $300 \times 10^{3}$ and the experimental data of the lift $\left(C_{l}\right)$ and drag $\left(C_{d}\right)$ coefficients variation with the angle of attacks $(A O A)$ have been investigated using different turbulence models. This is shown in figure 2. 
As shown in figures in figure 2 (a) and (b), the numerical results of SST k- $\omega$ model had good agreement with the experimental data at Reynolds number $1.6 \times 10^{6}$, except for small deviations in the

3 lift coefficient. On the other hand, in figure 2 (c), (d), (e) and (f), the transition SST model gave the 4 closest match with the expected data at Reynolds numbers of $460 \times 10^{3}$ and $300 \times 10^{3}$. Since separated

5 flow is directly connected to flow in the boundary layer, the transition SST turbulence model should best capture this critical phenomena for wind turbine applications [26]. Similar results have been found for other airfoils typically used with wind turbines, such as S822 [28].

As shown in figure 2 (e) and (f), using the transition SST turbulence model, the drag coefficient

9 values along the angle of attack variation at Reynolds number $300 \times 10^{3}$ are much higher compared to

10 the reference experimental data. However, the lift coefficient has lower values along the variation of

11 the angle of attack. This is due to the transitional separation bubble phenomenon. According to the

12 study presented by [27] for NACA 63415 airfoil, a transitional separation bubble occurs when the flow

13 over the airfoil experiences decreasing pressure causing it to separate from the surface. After the flow

14 separates, a detached shear layer form. A transition to turbulent flow occurs within the unstable shear

15 layer. In the turbulent flow, momentum transfer is enhanced, which leads to reattachment. The size of

16 the transitional separation bubble increases with decreasing Reynolds number. The boundary layer

17 forms over the top of the separation bubble and therefore the airfoil drag increases substantially. The

18 transitional separation bubble and thickening of the boundary layer also affects the airfoil lift.

19 As presented in the authors' previous study in reference [29], the grid contained 120,878 nodes,

20 and the height of the grid next to the airfoil surface was $7 \times 10^{-6} \mathrm{~m}$. The dimensionless wall distance

21 Y plus $\left(Y^{+}\right)$values were less than 1 over the entire airfoil surface.

After validating the 2D CFD simulation model at the three Reynolds number values with the

23 experimental results from [25] in clean air, the Discrete Phase Model was utilized to predict the effect

24 of sand particles concentration and angle of attack on the erosion rate of the blade. The sand particle

25 diameter $\left(d_{p}\right)$ for this study was selected as $250 \mu \mathrm{m}$ with a sand density of $2500 \mathrm{~kg} / \mathrm{m}^{3}$ based on studies 
1 in the Arabian Peninsula and Southern Africa [30, 31]. Three mass flow rate values were studied

2 during the CFD simulation. These values are $100 \mathrm{~kg} / \mathrm{s}, 200 \mathrm{~kg} / \mathrm{s}$ and $400 \mathrm{~kg} / \mathrm{s}$. Each mass flow value

3 is equivalent to a certain value of the characteristic ratio $(\alpha)$ between sand and air flow.

$4 \quad$ The Discrete Phase Model represents the sand particles in the continuous phase using round 5 particles. The trajectories, heat transfer and mass transfer of these discrete phase entities are computed 6 and simulated. Full coupling between the phases is included. The trajectory of the sand particle is 7 predicted by integrating the force balance on the particle. This force balance is presented in a 8 Lagrangian reference frame. The balance of the forces acting on the particle and the particle inertia, 9 can be presented as:

$11 \frac{d V_{p}}{d t}=\left[D_{p}\left(V_{r e l}-V_{P}\right)\right]+\left[\frac{g_{x}\left(\rho_{p}-\rho\right)}{\rho_{p}}\right]+m_{x}$

$12 D_{p}=\frac{18 \mu C_{d} R e_{p}}{\rho_{p} d_{p}^{2} 24}$

14 where, $D_{p}\left(V_{r e l}-V_{p}\right)$ is the drag force per unit particle mass, $m_{x}$ is the virtual mass flow which is

15 neglected since the density ratio between air to sand is very small, $V_{\text {rel }}$ is the fluid velocity relative to

16 the airfoil, $\mu$ is the fluid dynamic viscosity coefficient, $\rho$ is the air density, $\rho_{p}$ is the density of the sand

17 particle, $d_{p}$ is the sand particle diameter, $R e_{p}$ is the relative Reynolds number for the sand particle [32].

The characteristic ratio $(\alpha)$ between sand and air flow is

$\alpha=\frac{\text { Volumetric Flow Rate of Sand }}{\text { Volumetric Flow Rate of Air }}$

The erosion rate from particle impact is calculated for wall surfaces. The erosion rate is

22 calculated as:

$$
R_{\text {Erosion }}=\sum_{p=1}^{N_{\text {Particles }}} \frac{\dot{m}_{p} C\left(d_{p}\right) f(\Theta) v^{b(v)}}{A_{\text {face }}}
$$

Where $m_{p}$ is the mass flow rate of the injected discrete particles, $C\left(d_{p}\right)$ is a function of sand particle diameter, $\Theta$ is the impact angle of the particle path with the wall face, $f(\Theta)$ is a factor 
which is a function of impact angle, $v$ is the relative particle velocity, $b(v)$ is a function of relative particle velocity, and $A_{\text {face }}$ is the area of the cell face at the wall. Default values are $C=1.8 \times 10^{-}$

${ }^{9}, f=1$, and $b=0$ [32-34]. C, $\mathrm{f}$ and $\mathrm{b}$ values for sand eroding are given by Edwards et al.[35].

According to Lain and Sommerfeld [36], a multiphase flow simulation could be investigated using one-way coupling in sand/air flow cases with a characteristic ratio $(\alpha)$ up to $6.3 \times 10^{-4}$. Lain and

6 Sommerfeld [36] found a good agreement between the turbulence modelling strategies used and the experimental measurements by Tsuji et al. [37] in the multi-phase flow. Accordingly, the values of the characteristic ratio $(\alpha)$ for each Reynolds number were chosen up to $6.3 \times 10^{-4}$. Tables 1,2 and 3 represent the equivalent values of the characteristic ratio $(\alpha)$ for the three values of the mass flow rate

10 at each Reynolds number used in the CFD simulation.

Bose et al. [38], Monchaux and Dejoan [39] and Malloupas et al. [40] showed that two-way coupling makes some difference to the results even for $\alpha$ in the range of $10^{-5}$ to $10^{-4}$ if $\operatorname{Re}_{\lambda}<50$, where

$13 \operatorname{Re}_{\lambda}$ is the Reynolds number based on the Taylor microscale length. However, Mora et al. [41] found

14 that two-way coupling has some effect on dissipation and settling time for the fluid droplets in their 15 study with $\operatorname{Re}_{\lambda}$ up to 400 or 500 . For the flow conditions in the current study, $\operatorname{Re}_{\lambda}$ is in the range 3000 - 18000. Therefore, for $\mathrm{Re}_{\lambda}$ in the range used in the current study, one-way coupling should be adequate. Further discussion on simulation of small droplets can be found in [42-43].

Mass flow rate $400 \mathrm{~kg} / \mathrm{s}$ could not be simulated at Reynolds number of $300 \times 10^{3}$ as the value

19 of the characteristic ratio $(\alpha)$ in that case is higher than $6.3 \times 10^{-4}$, which is beyond the range verified 20 according to [36]. A high characteristic ratio would need a 4-way coupling model to include the particle 21 effects on turbulence and particle-particle interactions.

\subsection{Blade Element Momentum Model [24]}

BEM theory balances the axial force and moment generated on the rotor blades with changes in, respectively, the linear and angular momentum of the mass of air flowing through the rotor disc.

26 This equilibration considers the flow segmented through annular elements of width $d r$ as shown in 
1 figure 3. In the represented BEM model, it was assumed there was no radial dependency and the force

2 from the blades on the flow within each annular element is uniform [24]. The data were adjusted to

$3360^{\circ}$ polars based on the algorithms of Montgomerie and corrected for the tip losses (Prandtl's Loss

4 Factor correction). [15,44]. The elements near the root of the blade have angles of attack of greater

5 than 10 deg., so there is some loss of accuracy in extrapolating from the CFD data set. However, this

6 region accounts for only $15 \%$ of the power generated and has minimal erosion, so the overall accuracy

7 is only slightly affected.

8 The loads normal to the blade radius acting on the blade are shown in Figure 3.Also shown in

9 Fig. 3 are the angle of wind relative to the airfoil $(\varnothing)$, the angle of attack $(A O A)$, the axial and tangential

10 induction factors $(a)$ and $(a)$ that significantly affect the real value of the velocity $\left(V_{0}\right)$, and the element

11 normal (thrust) $\left(d F_{N}\right)$ and element tangential $\left(d F_{T}\right)$ forces which are generated by element lift $\left(d F_{l}\right)$ and

$12 \operatorname{drag}\left(d F_{d}\right)$ forces.

\subsubsection{Forces acting on each blade element:}

$15 d F_{N}=\frac{1}{2} \rho V_{r e l}^{2} c C_{n} d r$

$16 d F_{T}=\frac{1}{2} \rho V_{r e l}^{2} c C_{t} d r$

17 Where, $\rho$ is the air density, $V_{\text {rel }}$ is the relative velocity, $\mathrm{c}$ is the chord length, $\mathrm{C}_{1}$ is the lift coefficient

18 and $\mathrm{C}_{\mathrm{d}}$ is the drag coefficient,

$19 C_{n}=C_{l} \cos \Phi+C_{d} \sin \Phi$

20 and

$21 C_{t}=C_{l} \sin \Phi-C_{d} \cos \Phi$

22 From figure 3 it is readily seen from the geometry that:

$23 V_{\text {rel }} \sin \Phi=V_{0}(1-a)$

24 and

$25 \quad V_{r e l} \cos \Phi=\omega r(1+a ́)$ 
1 Where, $\omega$ is the rotational speed and $\mathrm{r}$ is the local radius.

2 The Thrust force $(d T)$ and the torque $(d M)$ on the control volume of thickness $d r$ are:

$3 \quad d T=b d F_{N} d r$

$4 \quad d M=b d F_{T} r d r$

5 Where, $\mathrm{b}$ is the number of wind turbine blades.

6 Using equation (11) for $F_{N}$ and equation (15) for $V_{\text {rel }}$, equation (17) becomes:

7

$8 \quad d T=\frac{1}{2} \rho b \frac{V_{0}^{2}(1-a)^{2}}{\sin ^{2} \emptyset} c C_{n} d_{r}$

9 Similarly, if equation (12) is used for $F_{T}$ and equations (15) and (16) are used for $V_{r e l}$, equation (18)

10 becomes:

$11 \quad d M=\frac{1}{2} \rho b \frac{V_{0}(1-a) \omega r(1+a)}{\sin \emptyset \cos \emptyset} c C_{t} r d_{r}$

\subsubsection{Rate of change of momentum:}

14 Conservation of linear momentum is

$15 d T=4 V_{0}^{2} \rho \pi r a(1-a) d r$

16 However, conservation of angular momentum is

$17 d M=4 V_{0} \rho \pi \omega r^{3} \dot{a}(1-a) d r$

Applying conservation of linear and angular momentum on a blade element of width dr, the

20 thrust force and moment supplied by a blade sector can be calculated from Equations (17) and (18).

21 The solution that simultaneously meets Equations (17), (18), (19) and (20) is found by iterating

22 respectively the axial and tangential induction factors $(a)$ and $(a)$. The total moment applied at the

23 rotor shaft is found by summing the partial moments, $\mathrm{dM}$, of each element of width $\mathrm{dr}$.

$24 P=\int \omega d M$

25 By summing over the elements, the power at the rotor shaft $(P)$ can determined using equation (19). 


\subsection{Erosion Prediction of NACA 63415 Using Neural Network}

Using the back-propagation ANN, the total amount of erosion occurred per unit length for the

3 HAWT blade made of NACA 63415 was estimated. Debris flow rate, Reynolds number and the angle

4 of attack are the operating conditions (input data). In MATLAB software version R2015a, the proposed

5 ANN was applied. Input, output and one or more hidden layers are there $[45,46]$. It was stated in Hertz

6 et al. [47] and Goh's [48] work that the three layers ANN give credible results in most of the study

7 cases. This statement was assured by the literature where ANNs were applied in process control. The

8 three layered ANN was used in almost all of these cases[47,49-52]. Therefore, this proposed ANN

9 consists of three-layer network, where it has in the hidden layer a sigmoid transfer function and in the

10 output layer a linear transfer function.

11 The sigmoid transfer function $g(\mathrm{~h})$ is

$13 g(\mathrm{~h})=\frac{1}{1+e^{-\beta h}}$

14 Where, $\beta$ is the rate constant. Three neurons form the input layer, only a single neuron forms

15 the output layer and eight neurons are found in the hidden layer. Trial and error reveal the optimum

16 number of hidden neurons. The implemented ANN in MATLAB software is shown in Figure 4 (a).

In a matrix, a set of input data were organized as columns. Into a second matrix, another set of

20 target data (the correct output for each of the input data) were arranged. From the CFD study mentioned

21 and discussed in the earlier section, these data were obtained. In table 4, the patterns used in the ANN

22 training progress are shown. From the ANN training progress, eight patters were excluded. However,

23 later on these patterns were used in the developed ANN to test its reliability. The excluded patterns are

24 presented in Table 5. The patterns used in the ANN training progress were normalized because the 25 sigmoid function's computed output can only be between 0 and 1.

Three sets were used where the ANN training progress were divided upon them randomly. The 
1 completely independent test of network generalization. The ANN outputs with respect to targets (the

2 correct CFD output for each of the input data) are shown in figure 4 (b) for training, validation, and

3 test sets. The data should fall along 45-degree line for a perfect fit, which means that the targets are

4 equal to the ANN outputs.

\subsection{Results and Discussion}

\subsection{Effects of Debris Flow on Lift Coefficient $\left(C_{l}\right)$ and Drag Coefficient $\left(C_{d}\right)$}

After the 2D CFD model was validated using experimental results for clean air flow, the Discrete Phase Model was used to study the airfoil performance in different debris flow conditions. The discrete phase particles were set to come out from the inlet with Reynolds number values of $1.6 \mathrm{x}$ $10^{6}, 460 \times 10^{3}$ and $300 \times 10^{3}$.

As shown in figure 5 (a), (b) and (c), the lift coefficient value increases with an increase in angle of attack due to the rise of the pressure difference between the high- and low-pressure sides for both clean and rough conditions. As the amount of debris flow rate increases by increasing the debris mass flow rate, the pressure coefficient difference between low- and high-pressure sides decreases as the momentum transfer between the Lagrangian and Eulerian increased.

On the other hand, as shown in figure 5 (d), (e) and (f), the drag coefficient increases with angle of attack, for both clean and rough conditions. As the angle of attack increases the drag coefficient increases more in rough conditions due to debris than in clean conditions. The inclusion of sand particles in the flow leads to a larger skin frictional drag and thus to larger total drag. The significant increase in the drag coefficient, combined with a decrease in lift, leads to a severe reduction of the aerodynamic performance of the airfoil. 
This section discusses the sand particles effect on the blade and the rate of erosion caused

2 during the 3-month annually. For Instance, in Egypt Khamasin sandstorm usually occurs between

3 March and May, carrying great quantities of sand and dust from the south into the north Africa [11].

4 The erosion rate variation with the chord length location $(\mathrm{x} / \mathrm{c})$ was studied at angles of attack of $2^{\circ}$ and

$510^{\circ}$. The erosion near the trailing edge at Reynolds numbers of $1.6 \times 10^{6}, 460 \times 10^{3}$ and $300 \times 10^{3}$ is

6 understood by following the particle trajectory presented in figure 6 . This figure show that at higher

7 AOA values, the area of direct contact between pressure side and mean flow increases, which in turn

8 increases the contact with sand particles. However, for smaller AOA values, the sand particles do not

9 come in contact with the trailing edge.

10 Figures from 7 show the erosion rate for a 3-months period of the suction side at angle of 11 attacks $2^{\circ}$ and $10^{\circ}$ at the three Reynolds number values. As shown in the figure, as the Reynolds 12 number value increases, the amount of erosion through the wind turbine airfoil increase. In addition,

13 the leading edge of the suction side is the most sensitive part where erosion is maximized. The erosion 14 rate could reach up to $0.6 \mathrm{~kg} / \mathrm{m}^{2}$ and $0.23 \mathrm{~kg} / \mathrm{m}^{2}$ in the high sandstorms concentration at Reynolds 15 number values of $1.6 \times 10^{6}$ and $460 \times 10^{3}$ respectively. However, in the case of low sand storms 16 concentration, erosion rate could be $0.07 \mathrm{~kg} / \mathrm{m}^{2}, 0.06 \mathrm{~kg} / \mathrm{m}^{2}$ and $0.04 \mathrm{~kg} / \mathrm{m}^{2}$ at Reynolds number values 17 of $1.6 \times 10^{6}, 460 \times 10^{3}$ and $300 \times 10^{3}$ respectively.

18 It is observed that the erosion extends more towards the trailing edge at lower values of the

19 Reynolds number and lower angles of attack. For Example, the erosion reached the chord length 20 location $(\mathrm{x} / \mathrm{c})$ at $0.04 \mathrm{~m}$ at Reynolds number of $1.6 \times 10^{6}$ and angle of attacks $2^{\circ}$. While, by decreasing 21 the Reynolds number value to $300 \times 10^{3}$, the erosion extended to the chord length location(x/c) of 0.14 $22 \mathrm{~m}$ at the same angle of attack value. On the other hand, at angle of attack $2^{\circ}$, the erosion almost reached 23 the chord length location $(\mathrm{x} / \mathrm{c})$ at $0.04 \mathrm{~m}, 0.11 \mathrm{~m}$ and $0.14 \mathrm{~m}$ at Reynold number values of $1.6 \times 10^{6}$, $24460 \times 10^{3}$ and $300 \times 10^{3}$ respectively. while, at angle of attack $10^{\circ}$, the erosion was very limited. This 
1 means that the suction side is less affected by the erosion caused due to the sand particles at the higher

2 angle of attack.

In contrast, figures from 8 to 13 represent the erosion rate of the pressure side at angle of attacks

$42^{\circ}$ and $10^{\circ}$. It is observed that, the erosion rate is maximized at higher angle of attacks. At angle of

5 attack $10^{\circ}$, the maximum erosion rate was almost $0.46 \mathrm{~kg} / \mathrm{m}^{2}$ and $0.3 \mathrm{~kg} / \mathrm{m}^{2}$ at Reynolds number values

6 of $1.6 \times 10^{6}$ and $460 \times 10^{3}$ respectively in the high sandstorm concentration. While, in case of low

7 sandstorm concentration, the maximum erosion rate at the same angle of attack value was $0.08 \mathrm{~kg} / \mathrm{m}^{2}$,

$80.04 \mathrm{~kg} / \mathrm{m}^{2}$ and $0.06 \mathrm{~kg} / \mathrm{m}^{2}$ at Reynolds number values of $1.6 \times 10^{6}, 460 \times 10^{3}$ and $300 \times 10^{3}$

9 respectively.

10 Compared to the suction side, the pressure side has an opposite eroding behavior with the

11 change of the angle of attack values. As the angle of attack increases, the pressure side is more affected

12 by the erosion caused due to the impact of sand particles. As shown in the figures, the erosion was

13 diffused all over the pressure side chord at AOA $10^{\circ}$ especially at Reynolds number values of $460 \mathrm{x}$

$1410^{3}$ and $300 \times 10^{3}$. Thus, this diffusion is significant at low Reynolds number values.

\subsection{Power Curve Output Using BEM Model}

The performance of the blade is directly related to its power coefficient $\left(C_{p}\right)$. Therefore, to

19 select an airfoil, the power coefficient of each blade should be found at the operational Reynolds 20 number.

Figure 14 (a) shows the $C_{p}$ of the wind turbine rotor versus the tip speed ratio (TSR) in the

22 clean and rough conditions due to debris flow. A maximum $C_{p}$ of approximately 0.38 occurs at TSR

23 of 9. Note that, because of the extrapolation used in the BEM model, the accuracy decreases with

24 decreasing TSR. For TSR $<7$, the data should be regarded as qualitative. For the clean condition case,

25 the wind turbine rotor can work very well for a TSR from 7.5 to 9.5 since the wind turbine blade nearly 
maintains the required $C_{p}$ value. However, as the debris mass flow rate increases, the maximum $C_{p}$

2 value obtained decreases. For the case of low debris flow, the maximum $C_{p}$ value obtained is 0.34 ,

3 which shows a $11 \%$ decrease when compared to clean operation condition. In addition, the maximum

$4 C_{p}$ value obtained, for the case of high debris flow, is almost 0.28 . This is a $26 \%$ decrease when compared to the clean operation condition. Figure 14 (b) presents the simulated torque coefficient $\left(C_{m}\right)$ produced for the clean rotor surface as well as rough surfaces for various sand/air volumetric ratios.

The maximum torque coefficient produced when wind turbine rotor operates in the clean condition is 0.05. This value could be decreased into 0.037 in case of high debris flow.

Figure 14 (c) shows the simulated power curves for the clean rotor surface as well as rough

10 surfaces for various sand/air volumetric ratios. This power output was optimized by changing the tip

11 speed ratio value to obtain the optimum value of Torque produced as presented in figure 14 (b).

12 According to figure 14 (c) and the results of this investigation, surface roughness caused by debris can

13 results in a high-energy yield deficit. For the case studied, the decrease in power is predicted to be $10 \%$

14 for low debris flow but could reach $30 \%$ for high debris flow compared to clean air.

\subsection{Nordtank NTK 500/41 Wind Turbine Case Study}

Large-scale Wind turbines (LSWT) with a rated power of 50kW-1 MW are a mature technology and should experience rapid growth in coming decades [5]. Nordtank NTK 500/41 is an example of a large-scale commercial wind turbine which produces a rated power of $500 \mathrm{~kW}$. This wind turbine was installed in 1992 for testing and its performance was investigated extensively during 19921999 [53]. The NTK 500/41 is a stall regulated (fixed pitch) turbine with fixed rotational speed control strategy. Table 6 shows the main parameters of Nordtank NTK 500/41 [53].

Using QBlade software and the above rotor simulation curves, the wind turbine power curve

24 produced by the Nordtank NTK 500/41wind turbine was simulated for wind speeds $4-25 \mathrm{~m} / \mathrm{s}$. The mechanical power available from the blades shown in Fig. 14 (c) was used by the QBlade simulation 
1 for operating the wind turbine at its optimal tip speed ratio for maximum electrical power generation.

2 When the electrical generation load is applied, the blades will rotate at a slower speed than the stall

3 limited rotational speed, and the electrical power output will therefore be reduced compared to the

4 mechanical power from the blades shown in Fig. 14 (c). Figure 14 (d) presents Nordtank NTK 500/41

5 power curve at different wind speeds in clean and rough conditions. The power curve is oscillating at

6 the end of it due to small errors in the iterative calculation, which are magnified in the power output

7 for high wind speeds. Under sandstorm conditions, the power losses from debris flow seen in Figure

814 (d) would directly affect the turbine power. For the current case study, the maximum power loss is

9 almost $8 \%, 14 \%$ and $22 \%$ in low, medium and high debris flow concentrations, respectively.

\subsection{Neural Network Erosion Per Unit Area Prediction}

After the training process of the proposed ANN has been done, the eight excluded patterns

13 were used to test the reliability of this developed ANN. The ANN and CFD outputs were compared

14 and the absolute percentage error (APE) for each pattern was calculated. Figure 15 (a) shows a

15 comparison between the CFD and ANN output for the total erosion on chord per unit area for each

16 pattern used in the reliability test for the developed neural network. Figure 15 (b) APE between the

17 CFD and ANN output for the total erosion on chord per unit area for each pattern used in the reliability

18 test for the developed neural network. As seen in the figure, the average APE is $9.42 \%$, the maximum

19 APE is $14.58 \%$ and the minimum APE is $4.33 \%$. Figure 15 (c) shows the APE between the CFD and

20 ANN output for the total erosion on chord per unit area for all the patterns used in the ANN training

21 progress and the reliability test. It has also been listed in the last column in table 4. According to [54],

22 the average APE is used to evaluate the approximation performance precision of the ANN models.

23 The average APE of this constructed metamodel is $4.91 \%$. This value is normally considered

24 acceptable, and should be given particular consideration since, according to the literature survey, this

25 is the first ANN model which could estimate the HAWT rate of erosion. Increasing the patterns of the 
1 input and output data in the training process helps to maximize the approximation accuracy of this

2 neural network model. However, this increased training will increase the computational cost and

3 potentially reduce the applicability of the model to other new scenarios.

\subsection{Conclusion}

In this work, the effect of debris/air flow on the aerodynamic performance of horizontal axis

6 wind turbines (HAWT) was investigated using CFD-BEM modelling. Before evaluating the rotor

7 performance using BEM theory, lift and drag coefficients were obtained as a function of angle of attack

8 through 2D CFD simulations. The CFD simulation results were validated using experimental data in

9 the clean condition. Then the lift and drag coefficient values during debris flow simulations were

10 obtained from CFD and used in the BEM theory. Large-scale Wind turbines case study was presented.

11 Power curves for the wind turbine rotor were obtained and estimated in different debris flow values.

12 Results based on the BEM method showed that the power generated under sandstorm conditions can

13 decrease $30 \%$ compared to normal conditions. An artificial neural network has been proposed to

14 predict the total amount of erosion occurred per unit area as a function of the operating conditions of

15 the wind turbine blade, which are: the debris flow rate, the Reynolds number and the angle of attack.

16 Therefore, researchers working on wind turbine design, optimization, diagnosis and maintenance

17 should be aware of the debris flow issues.

\section{ACKNOWLEDGMENT}

20 The authors acknowledge the support of the Arab Academy for Science, Technology and Maritime 21 Transport.

\section{Data Availability}

24 The data that supports the findings of this study are available within the article. 
1. Lanzafame, R. and M. Messina, Fluid dynamics wind turbine design: Critical analysis, optimization and application of BEM theory. Renewable Energy, 2007. 32(14): p. 2291-2305. inside of a 1-D Numerical Code. Renewable Energy, 2012. 39(1): p. 440-446.

3. Bavanish, B. and K. Thyagarajan, Optimization of Power Coefficient on a Horizontal Axis Wind Turbine Using BEM Theory. Renewable and Sustainable Energy Reviews, 2013. 26: p. 169-182.

4. Ghadirian, A., M. Dehghan, and F. Torabi, Considering Induction Factor using BEM Method in Wind Farm Layout Optimization. Journal of Wind Engineering and Industrial Aerodynamics, 2014. 129: p. 31-39.

5. Bai, C.-J. and W.-C. Wang, Review of Computational and Experimental Approaches to Analysis of Aerodynamic Performance in Horizontal-Axis Wind Turbines (HAWTs). Renewable and Sustainable Energy Reviews, 2016. 63: p. 506-519.

6. Esfahanian, V., A. Salavati Pour, I. Harsini, A. Haghani, R. Pasandeh, A. Shahbazi, and G. Ahmadi, Numerical Analysis of Flow Field Around NREL Phase II Wind Turbine by a Hybrid CFD/BEM Method. Journal of Wind Engineering and Industrial Aerodynamics, 2013. 120: p. 29-36.

7. Yang, H., W. Shen, H. Xu, Z. Hong, and C. Liu, Prediction of the Wind Turbine Performance by Using BEM with Airfoil Data Extracted from CFD. Renewable Energy, 2014. 70: p. 107115.

8. $\quad$ Shehata, A.S., Saqr, K.M., Xiao, Q., Shehadeh, M.F., Day, A. Performance analysis of wells turbine blades using the entropy generation minimization method. Renewable Energy, 2016. 87: p.1123-1133.

9. Guo, Q., L. Zhou, and Z. Wang, Comparison of BEM-CFD and full rotor geometry simulations for the performance and flow field of a marine current turbine. Renewable Energy, 2015. 75: p. 640-648.

10. Gharali, K. and D.A. Johnson, Numerical Modeling of an S809 Airfoil under Dynamic Stall, Erosion and High Reduced Frequencies. Applied Energy, 2012. 93: p. 45-52.

11. Zidane, I.F., K.M. Saqr, G. Swadener, X. Ma, and M.F. Shehadeh, On the role of surface roughness in the aerodynamic performance and energy conversion of horizontal wind turbine blades: a review. International Journal of Energy Research, 2016. 40(15): p. 2054-2077.

12. Iham F. Zidane, G.S., Khalid M. Saqr, Xianghong Ma, Mohamed F. Shehadeh. CFD Investigation of Transitional Separation Bubble Characteristics on NACA 63415 Airfoil at Low Reynolds Numbers. in Proceedings of the 25th UKACM Conference on Computational Mechanics. 2017. Birmingham, United Kingdom.

13. Akour, S.N., M. Al-Heymari, T. Ahmed, and K.A. Khalil, Experimental and theoretical investigation of micro wind turbine for low wind speed regions. Renewable Energy, 2018. 116: p. 215-223.

14. Darbandi, M., A. Mohajer, A. Behrouzifar, R. Jalali, and G.E. Schneider, Evaluating the Effect of Blade Surface Roughness in Megawatt Wind Turbine Performance Using Analytical and Numerical Approaches, in 10th International Conference on Heat Transfer, Fluid Mechanics and Thermodynamics. 2014: Orlando, Florida.

15. Pechlivanoglou, G., S. Fuehr, C.N. Nayeri, and C.O. Paschereit, The Effect of Distributed Roughness on the Power Performance of Wind Turbines, in Proceedings of ASME Turbo Expo 2010: Power for Land, Sea and Air GT2010. 2010: Glasgow, UK.

16. Chen, X. and R. Agarwal, Optimization of Flatback Airfoils for Wind Turbine Blades Using a Genetic Algorithm with an Artificial Neural Network, in 48th AIAA aerospace Sciences 
21. Momoh, J.A. and R. Button, Design and Analysis of Aerospace DC Arcing Faults using Fast Fourier Transformation and Artificial Neural Network in IEEE Power Engineering Society General Meeting 2003: Toronto, Ont., Canada.

22. Zhang, Z., Automatic Fault Prediction of Wind Turbine Main Bearing Based on SCADA Data and Artificial Neural Network. Open Journal of Applied Sciences, 2018. 08(06): p. 211-225.

23. Marten, D., J. Wendler, G. Pechlivanoglou, C.N. Nayeri, and C.O. Paschereit, Qblade: an Open Source Tool for Design and Simulation of Horixontal and Vertical Axis Wind Turbines. International Journal of Emerging Technology and Advanced Engineering, 2013. 3(3): p. 264-269.

24. Hansen, M., Aerodynamics of wind turbines Second ed. 2008, UK: Earthscan.

25. Bak, C., P. Fuglsang, J. Johansen, and I. Antoniou, Wind Tunnel Tests of NACA 63-415 and a Modified NACA 63-415 Airfoil, in Ris $\varnothing$ National Laboratory. 2000: Roskilde, Denmark.

26. Lanzafame, R., S. Mauro, and M. Messina, Wind Turbine CFD Modeling Using a Correlation-Based Transitional Model. Renewable Energy, 2013. 52: p. 31-39.

27. Zidane, I.F., G. Swadener, K.M. Saqr, X. Ma, and M.F. Shehadeh, CFD Investigation of Transitional Separation Bubble Characteristics on NACA 63415 Airfoil at Low Reynolds Numbers, in Proceedings of the 25th UKACM Conference on Computational Mechanics. 2017: University of Birmingham, United Kingdom.

28. Giguere, P. and M.S. Selig,Low Reynolds Number Airfoils for Small Horizontal Axis Wind Turbines Wind Engineering, 1997. 21: p. 367-380.

29. Zidane, I.F., K.M. Saqr, G. Swadener, X. Ma, and M.F. Shehadeh, Computational Fluid Dynamics Study of Dusty Air Flow over Naca 63415 Airfoil for Wind Turbine Applications. Jurnal Teknologi, 2017. 79(7-3).

30. T. Mahdaoui, N.B., M. A. Madjoubi, C. Bousbaa, Study of the Effects of Sand Blasting on Soda Lime Glass Erosion. INTERNATIONAL REVIEW OF MECHANICAL ENGINEERING, 2007. 1: p. 502-510.

31. Henley, P., Unpublished soil sample report, Remote Sensing Division, Resewcl Institute, U.S. Army Engineer Topographic Laboratories, Ft Belvoir, VA,. 21 Nov 90.

32. FLUENT, A., Theory Guide. 2011.

33. Douvi, E.C. and D.P. Margaris, Aerodynamic Performance Investigation under the Influence of Heavy Rain of a NACA 0012 Airfoil for Wind Turbine Applications'. International Review of Mechanical Engineering, 2012. 6(6): p. 1228-1235.

34. Morsi, S.A. and A.J. Alexander, An Investigation of Particle Trajectories in Two Phase Flow Systems. Journal of Fluid Mechanics, 1972. 55(2): p. 193- 208. 
35. J. K. Edwards, B.S.M., and S. A.Shirazi, Evaluation of Alternative Pipe Bend Fittings in Erosive Service, in In Proceedings of ASME FEDSM'00: ASME 2000 Fluids Engineering Division Summer Meeting. 2000: Boston, MA.

36. Lain, S. and M. Sommerfeld, Turbulence modulation in dispersed two-phase flow laden with solids from a Lagrangian perspective. International Journal of Heat and Fluid Flow, 2003. 24(4): p. 616-625.

37. Tsuji, Y., Morikawa, Y., Shiomi, H., LDV measurements of an air-solid two-phase flow in a vertical pipe. J. Fluid Mech, 1984. 139: p. 417-434.

38. Bose, T., L. Kleiser, and E. Meiberg, Small particles in homogenous turbulence: Settling velocity enhancement by two-way coupling, Phys. Fluids, 2006. 18: 027102.

39. Monchaux, R. and A. Dejoan, Settling velocity and preferential concentration of heavy particles under two-way coupling effects in homogenous turbulence, Phys. Rev. Fluids, 2017. 2: 104302.

40. Mallouppas, G., W. K. George, and B. G. M. van Wachem, Dissipation and inter-scale transfer in fully coupled particle and fluid motions in homogeneous isotropic forced turbulence, Intl. J. Heat Fluid Flow, 2017. 67 (B): 74-85.

41. Mora, D. O., A. Cartellier, M. Obligado, Experimental estimation of trbulence modification by internal particles at moderate Re $\lambda$, Phys. Rev. Fluids, 2019. 4: 074309.

42. Biferale, L., C. Meneveau, R. Vericco, Deformation statistics of sub-Kolmorogorov-scale ellipsoidal neutrally buoyant drops in isotropic turbulence, J. Fluid Mech, 2014. 754: p. 184207.

43. Spandan, V., D. Lohse, R. Verrico, Deformation and orientation statistics of neutrally buoyant sub-Kolmorogorov ellipsoidal droplets in turbulent Taylor-Couette flow, J. Fluid Mech, 2016. 809: p. 480-501.

44. Montgomerie, B., Methods for root effects, tip effects and extending the angle of atack range to $\pm 180 o$, with application to aerodynamics for blades on wind turbines and propellers. 2004, Scientific report FOI-R-1305-SE, FOI Swedish defence research agency.

45. Roffel, B. and B. Betlem, Process Dynamics and Control. 2006: John Wiley and Sons, Ltd.

46. Rumelhart, D.E., G.E. Hinton, and R.J. Williams, Learning Internal Representations by Error Propagation. Parallel Distributed Processing, 1986. 1: p. 318-62.

47. Hertz, J., A. Krogh, and R.G. Palmer, Introduction to the Theory of Neural Computation. 1995, Redwood City: Addison-Wesley Publishing Company.

48. Goh, A.T.C., Back-propagation neural networks for modeling complex systems. Artificial Intelligence in Engineering, 1995. 9: p. 143-151.

49. López, P., R. Velo, and F. Maseda, Effect of Direction on Wind Speed Estimation in Complex Terrain Using Neural Networks. Renewable Energy, 2008. 33(10): p. 2266-2272.

50. Fadare, D., The Application of Artificial Neural Networks to Mapping of Wind Speed Profile for Energy Application in Nigeria. Appl Energy, 2010. 87: p. 934-42.

51. Yang, S., W. Li, and C. Wang, The Intelligent Fault Diagnosis of Wind Turbine Gearbox Based on Artificial Neural Network. In: Proceedings International Conference on Condition Monitoring and Diagnosis, 2008: p. 1327-30.

52. Ata, R., Artificial Neural Networks Applications in Wind Energy Systems: A Review. Renewable and Sustainable Energy Reviews, 2015. 49: p. 534-562.

53. Hansen, K.S., K.O.H. Pedersen, and U.S. Paulsen, Online wind turbine measurement laboratory, in EWEC 2006. 2006: Athens. p. 1-8.

54. Ju, Y., C. Zhang, and L. Ma, Artificial Intelligence Metamodel Comparison and Application to Wind Turbine Airfoil Uncertainty Analysis. Advances in Mechanical Engineering, 2016. 8(5): p. 1-14. 
Table 1 The equivalent values of the characteristic ratio between the sand and air $(\alpha)$ for the three mass flow rate values at Reynolds number 1.6 million.

\begin{tabular}{|c|c|}
\hline Mass Flow Rate (kg/s) & Characteristic Ratio Between the Sand and Air $(\boldsymbol{\alpha})$ \\
\hline 100 & $0.4 \times 10^{-4}$ \\
\hline 200 & $0.9 \times 10^{-4}$ \\
\hline 400 & $1.7 \times 10^{-4}$ \\
\hline
\end{tabular}

Table 2 The equivalent values of the characteristic ratio between the sand and air $(\alpha)$ for the three mass flow rate values at Reynolds number 460,000.

\begin{tabular}{|c|c|}
\hline Mass Flow Rate (kg/s) & Characteristic Ratio Between the Sand and Air $(\boldsymbol{\alpha})$ \\
\hline 100 & $1.5 \times 10^{-4}$ \\
\hline 200 & $3.0 \times 10^{-4}$ \\
\hline 400 & $5.9 \times 10^{-4}$ \\
\hline
\end{tabular}

Table 3 The equivalent values of the characteristic ratio between the sand and air $(\alpha)$ for the three mass flow rate values at Reynolds number 300,000.

\begin{tabular}{|c|c|}
\hline Mass Flow Rate (kg/s) & Characteristic Ratio Between the Sand and Air $(\boldsymbol{\alpha})$ \\
\hline 100 & $2.3 \times 10^{-4}$ \\
\hline 200 & $4.5 \times 10^{-4}$ \\
\hline
\end{tabular}

Table 4 Input and output patterns for CFD and neural network

\begin{tabular}{|c|c|c|c|c|c|c|}
\hline \multirow{2}{*}{$\begin{array}{l}\text { Pattern } \\
\text { Number }\end{array}$} & \multicolumn{3}{|c|}{ Input Data } & \multirow{2}{*}{$\begin{array}{c}\text { CFD Output } \\
\text { Data } \\
\text { Total } \\
\text { Erosion on } \\
\text { Chord } \\
\left(\mathrm{g} / \mathrm{m}^{2}\right)\end{array}$} & \multirow{2}{*}{$\begin{array}{c}\text { ANN Output } \\
\text { Data } \\
\text { Total } \\
\text { Erosion on } \\
\text { Chord } \\
\left(\mathrm{g} / \mathrm{m}^{2}\right)\end{array}$} & \multirow{2}{*}{$\begin{array}{c}\text { ANN } \\
\text { Percentage } \\
\text { Error - } \\
\text { Absolute } \\
\text { Value(\%) }\end{array}$} \\
\hline & $\begin{array}{c}\text { Debris } \\
\text { Flow } \\
\text { Rate(kg/s) }\end{array}$ & $\begin{array}{l}\text { Reynolds } \\
\text { Number }\end{array}$ & AOA & & & \\
\hline 1 & 100 & 300000 & 0 & 579 & 613 & 5.95 \\
\hline 2 & 100 & 300000 & 2 & 654 & 705 & 7.79 \\
\hline 3 & 100 & 300000 & 4 & 695 & 664 & 4.43 \\
\hline 4 & 100 & 300000 & 6 & 620 & 710 & 14.53 \\
\hline 5 & 100 & 300000 & 8 & 1069 & 993 & 7.07 \\
\hline 6 & 100 & 300000 & 10 & 1008 & 1024 & 1.61 \\
\hline 7 & 200 & 300000 & 0 & 1387 & 1356 & 2.19 \\
\hline 8 & 200 & 300000 & 2 & 1266 & 1139 & 10.02 \\
\hline 9 & 200 & 300000 & 4 & 1000 & 983 & 1.70 \\
\hline 10 & 200 & 300000 & 6 & 1475 & 1543 & 4.66 \\
\hline 11 & 200 & 300000 & 8 & 2719 & 2536 & 6.72 \\
\hline 12 & 200 & 300000 & 10 & 1944 & 1945 & 0.07 \\
\hline
\end{tabular}




\begin{tabular}{|c|c|c|c|c|c|c|}
\hline 13 & 100 & 460000 & 2 & 790 & 709 & 10.25 \\
\hline 14 & 100 & 460000 & 4 & 655 & 684 & 4.50 \\
\hline 15 & 100 & 460000 & 6 & 797 & 694 & 12.98 \\
\hline 16 & 100 & 460000 & 8 & 855 & 905 & 5.91 \\
\hline 17 & 100 & 460000 & 10 & 1140 & 1021 & 10.50 \\
\hline 18 & 200 & 460000 & 0 & 1538 & 1315 & 14.47 \\
\hline 19 & 200 & 460000 & 2 & 1306 & 1349 & 3.28 \\
\hline 20 & 200 & 460000 & 4 & 965 & 1025 & 6.18 \\
\hline 21 & 200 & 460000 & 6 & 1321 & 1211 & 8.28 \\
\hline 22 & 200 & 460000 & 8 & 1866 & 2029 & 8.73 \\
\hline 23 & 200 & 460000 & 10 & 2282 & 2284 & 0.08 \\
\hline 24 & 400 & 460000 & 0 & 2457 & 2455 & 0.08 \\
\hline 25 & 400 & 460000 & 2 & 1997 & 2013 & 0.81 \\
\hline 26 & 400 & 460000 & 4 & 1759 & 1751 & 0.45 \\
\hline 27 & 400 & 460000 & 6 & 2255 & 2061 & 8.62 \\
\hline 28 & 400 & 460000 & 8 & 2926 & 2636 & 9.91 \\
\hline 29 & 400 & 460000 & 10 & 3645 & 3610 & 0.97 \\
\hline 30 & 100 & 1600000 & 0 & 770 & 819 & 6.40 \\
\hline 31 & 100 & 1600000 & 2 & 575 & 541 & 6.01 \\
\hline 32 & 100 & 1600000 & 4 & 389 & 342 & 12.00 \\
\hline 33 & 100 & 1600000 & 6 & 655 & 657 & 0.34 \\
\hline 34 & 100 & 1600000 & 8 & 832 & 868 & 4.31 \\
\hline 35 & 100 & 1600000 & 10 & 832 & 801 & 3.75 \\
\hline 36 & 200 & 1600000 & 0 & 1539 & 1526 & 0.85 \\
\hline 37 & 200 & 1600000 & 2 & 1151 & 1001 & 12.97 \\
\hline 38 & 200 & 1600000 & 4 & 890 & 891 & 0.16 \\
\hline 39 & 200 & 1600000 & 6 & 1234 & 1210 & 1.98 \\
\hline 40 & 200 & 1600000 & 8 & 1663 & 1686 & 1.41 \\
\hline 41 & 200 & 1600000 & 10 & 1554 & 1501 & 3.39 \\
\hline 42 & 400 & 1600000 & 0 & 3078 & 3076 & 0.05 \\
\hline 43 & 400 & 1600000 & 2 & 2457 & 2456 & 0.03 \\
\hline 44 & 400 & 1600000 & 4 & 1554 & 1621 & 4.30 \\
\hline 45 & 400 & 1600000 & 6 & 2621 & 2619 & 0.07 \\
\hline 46 & 400 & 1600000 & 8 & 3808 & 3807 & 0.03 \\
\hline 47 & 400 & 1600000 & 10 & 3107 & 3102 & 0.18 \\
\hline
\end{tabular}

Table 5 The Excluded input and output patterns from the neural network training progress 


\begin{tabular}{|c|c|c|c|c|c|c|}
\hline \multirow{2}{*}{$\begin{array}{l}\text { Testing } \\
\text { Pattern } \\
\text { Number }\end{array}$} & \multicolumn{3}{|c|}{ Input Data } & \multirow{2}{*}{$\begin{array}{c}\begin{array}{c}\text { CFD Output } \\
\text { Data }\end{array} \\
\text { Total } \\
\text { Erosion on } \\
\text { Chord } \\
\left(\mathrm{g} / \mathrm{m}^{2}\right)\end{array}$} & \multirow{2}{*}{$\begin{array}{c}\text { ANN Output } \\
\text { Data } \\
\text { Total } \\
\text { Erosion on } \\
\text { Chord } \\
\left(\mathrm{g} / \mathrm{m}^{2}\right)\end{array}$} & \multirow{2}{*}{$\begin{array}{c}\text { ANN } \\
\text { Percentage } \\
\text { Error (\%)- } \\
\text { Absolute } \\
\text { Value }\end{array}$} \\
\hline & $\begin{array}{c}\text { Debris } \\
\text { Flow Rate } \\
(\mathrm{kg} / \mathrm{s})\end{array}$ & $\begin{array}{c}\text { Reynolds } \\
\text { Number }\end{array}$ & AOA & & & \\
\hline 4 & 100 & 300000 & 6 & 620 & 710.3860241 & 14.58 \\
\hline 8 & 200 & 300000 & 2 & 1266 & 1139.177416 & 10.02 \\
\hline 14 & 100 & 460000 & 4 & 655 & 684.0733472 & 4.44 \\
\hline 21 & 200 & 460000 & 6 & 1321 & 1211.315698 & 8.30 \\
\hline 27 & 400 & 460000 & 6 & 2255 & 2060.659089 & 8.62 \\
\hline 32 & 100 & 1600000 & 4 & 389 & 341.9535792 & 12.09 \\
\hline 37 & 200 & 1600000 & 2 & 1151 & 1001.485368 & 12.99 \\
\hline 44 & 400 & 1600000 & 4 & 1554 & 1621.22193 & 4.33 \\
\hline
\end{tabular}

Table 6: The main parameters of Nordtank NTK 500/41

\begin{tabular}{|l|l|}
\hline Rotational Speed & $27.1 \mathrm{rpm}$ \\
\hline Rotor Radius & $20.5 \mathrm{~m}$ \\
\hline Number of Blades & 3 \\
\hline Cut-in Wind Speed & $4 \mathrm{~m} / \mathrm{s}$ \\
\hline Cut-out Wind Speed & $25 \mathrm{~m} / \mathrm{s}$ \\
\hline Profile & NACA 63-4xx \\
\hline
\end{tabular}




\section{Figure Captions}

Figure 1. shows the layout of the wind turbine blade and the airfoil used

Figure 2. Validation of lift $\left(\mathrm{C}_{1}\right)$ and drag $\left(\mathrm{C}_{\mathrm{d}}\right)$ coefficients for the current study: (a) lift coefficient for NACA 63415 at Reynolds Number $1.6 \times 10^{6}$ (b) drag coefficient at Reynolds Number for NACA 634151.6 X10 ${ }^{6}$ (c) lift coefficient for NACA 63415 at Reynolds Number $460 X 10^{3}$ (d) drag coefficient for NACA 63415 at Reynolds Number 460X10(e) lift coefficient for NACA 63415 at Reynolds Number 300X10³ (f) drag coefficient for NACA 63415 at Reynolds Number $300 \times 10^{3}$. Experimental results from Bak et al. [25] all for Re 1.6X10 $0^{6}$ and shown in all graphs for comparison.

Figure 3. Velocities and forces related to the wind turbine blade

Figure 4. (a) Implemented Neural Network in MATLAB software (b) The neural network outputs with respect to targets (the correct CFD output for each of the input data) for training, validation, and test sets

Figure 5. lift $\left(\mathrm{C}_{\mathrm{l}}\right)$ and drag $\left(\mathrm{C}_{\mathrm{d}}\right)$ coefficients Variation with angle of attacks in clean and sandy conditions. (a) lift coefficient at Reynolds Number $1.6 \times 10^{6}$ (b) lift coefficient at Reynolds Number $460 \times 10^{3}$ (c) lift coefficient at Reynolds Number $300 \times 10^{3}$ (d) drag coefficient at Reynolds Number $1.6 \times 10^{6}$ (e) drag coefficient at Reynolds Number $460 X 10^{3}$ (f) drag

Figure 6. Particle traces colored by particle velocity magnitude at angle of attack $2^{\circ}$ and $10^{\circ}$ (a) Reynolds number $1.6 \times 10^{6}$ (b) Reynolds number $460 \times 10^{3}$ (c) Reynolds number $300 \times 10^{3}$

Figure 7. Suction side erosion (a) Erosion at Reynolds number $1.6 \times 10^{6}$ and AOA $2^{\circ}$ (b) Erosion at Reynolds number $1.6 \times 10^{6}$ and $\mathrm{AOA} 10^{\circ}$ (c) Erosion at Reynolds number $460 \times 10^{3}$ and AOA $2^{\circ}$ (d) Erosion at Reynolds number $460 \mathrm{X} 10^{3}$ and $\mathrm{AOA} 10^{\circ}$ (e) Erosion at Reynolds number $300 \mathrm{X} 10^{3}$ and AOA $2^{\circ}$ (f) Erosion at Reynolds number $300 \mathrm{X} 10^{3}$ and AOA $10^{\circ}$. Only selected regions are shown for clarity. For locations not shown within the range in any figure, the erosion is zero.

Figure 8. Pressure side erosion rate for 3-months period annually at Reynolds number of $1.6 \times 10^{6}$ and $\mathrm{AOA}$ of $2^{\circ}$ for NACA 63415

Figure 9. Pressure side erosion rate for 3-months period annually at Reynolds number of 1.6 X $10^{6}$ and $\mathrm{AOA}$ of $10^{\circ}$ for NACA 63415

Figure 10. Pressure side erosion rate for 3 -months period annually at Reynolds number of $460 \times 10^{3}$ and $\mathrm{AOA}$ of $2^{\circ}$ for NACA 63415

Figure 11. Pressure side erosion rate for 3 -months period annually at Reynolds number of $460 \times 10^{3}$ and $\mathrm{AOA}$ of $10^{\circ}$ for NACA 63415 (a) Chord range (x/c) from 0 to 0.5 (a) Chord range (x/c) from 0 to 0.5 
Figure 12. Pressure side erosion rate for 3 -months period annually at Reynolds number of $300 \times 10^{3}$ and $\mathrm{AOA}$ of $2^{\circ}$ for NACA 63415

Figure 13. Pressure side erosion rate for 3-months period annually at Reynolds number of $300 \mathrm{X} 10^{3}$ and $\mathrm{AOA}$ of $10^{\circ}$ for NACA 63415 (a) Chord range (x/c) from 0 to 0.5 (a) Chord range (x/c) from 0 to 0.5

Figure 14. (a) Power Coefficient Vs TSR using BEM Model in clean and sandy conditions (b) Torque Coefficient Vs TSR using BEM Model in clean and sandy conditions (c) Power Output using BEM Model in clean and sandy conditions (d) Nordtank NTK 500/41 power curve at different wind speeds in clean and rough conditions

Figure 15. (a) Comparison between the CFD and neural network output values for the total erosion on chord per unit area (b) The absolute percentage error between the CFD and neural network output values for the total erosion on chord per unit area for each pattern used in the reliability test (c) The absolute percentage error between the CFD and neural network output values for the total erosion on chord per unit area for the whole patterns used in neural network training process and reliability test. 